\title{
Deletion of Chromosome 22 Associated Meningioma
}

National Cancer Institute

\section{Source}

National Cancer Institute. Deletion of Chromosome 22 Associated Meningioma. NCI Thesaurus. Code C5305.

A meningioma that is associated with deletion of chromosome 22. This abnormality is the most consistent cytogenetic finding that is detected in meningiomas. 